\title{
"AGORA INÊS É MORTA": MARCAS (QUASE IRREVERSÍVEIS) DE FORMAÇÃO E DE AFETO EM CONTOS ILUSTRADOS PARA CRIANÇAS
}

Beatriz dos Santos Feres (UFF)

Resumo: Partindo-se do pressuposto de que os bens culturais direcionados prioritariamente para crianças são instrumentos de socialização por meio dos quais são partilhados símbolos, estruturas comunicativas, comportamentos, crenças e valores, a composição verbo-visual dos textos ilustrados pode ser compreendida como arena propícia à problematização de temas relevantes para a infância e à inculcação de ideias referendadas por um grupo social. Para além do aspecto temático-ideológico, parece igualmente relevante destacar que, no conjunto formado pela palavra e pela imagem, são utilizadas estratégias discursivas especialmente voltadas para a captação do leitor iniciante e para a projeção persuasiva. Assim, neste artigo, pretende-se identificar estratégias verbo-visuais utilizadas para fazer saber, fazer crer e fazer sentir direcionadas à expressão do amor em narrativas cujo leitor preferencial é a criança. Para isso, propõe-se a análise dos contos ilustrados "A lenda de Pedro e Inês", de Margarida Almeida e Margarida Lisboa Pina (Kadernu, 2014) e "Inês", de Roger Mello e Mariana Massarani (Companhia das Letrinhas, 2015), nos quais se observam estratégias discursivas e poéticas utilizadas para a disseminação de um imaginário sensível. Fundamenta-se esta análise em Teorias da Literatura Infantil (COLOMER, 2017; RAMOS, 2011), na Teoria Semiolinguística de Análise do Discurso (CHARAUDEAU, 2007), na Sociologia da Comunicação (ESTEVES, 2016) e na Semiótica de base peirciana (PEIRCE, 2001; SANTAELLA; NÖTH, 2005).

Palavras-chave: Contos ilustrados; Discurso amoroso; Literatura infantil

Abstract: Based on the assumption that cultural goods aimed primarily at children are tools of socialization through which symbols, communicative structures, behaviors, beliefs and values are shared, the verb-visual composition of the illustrated texts can be understood as an appropriate arena to discuss relevant issues to childhood and to impose ideas endorsed by a social group.In addition to the thematicideological aspect, it also seems relevant to highlight that, in the set 
formed by word and image, discursive strategies are mainly used to capture the beginning reader and for the persuasive projection. Therefore, in this paper, it is intended to identify verb-visual strategies used to make known, make believe and make feel directed to the expression of love in narratives whose preferred reader is the child. For this end, it is proposed the analysis of the picturebooks " $A$ lenda de Pedro e Inês", by Margarida Almeida e Margarida Lisboa Pina (Kadernu, 2014) and "Inês", by Roger Mello e Mariana Massarani (Companhia das Letrinhas, 2015), in which discursive and poetic strategies are used to disseminate a sensitive imaginary. This analysis is based on Theories of Children's Literature (COLOMER, 2017; RAMOS, 2011), the Semiolinguistic Theory of Discourse Analysis (CHARAUDEAU, 2007), the Sociology of Communication (ESTEVES, 2016) and Semiotics (PEIRCE, 2001; SANTAELLA; NÖTH, 2005).

Keywords: Picturebooks; Discourse of love; Children Literature.

\section{"AGORA INÊS É MORTA": INCULCAÇÃO DE UM DISCURSO AMOROSO}

[A literatura] é fator indispensável de humanização.

Antonio Candido (2004)

"Agora Inês é morta": ditados populares como esse se instauram no imaginário das sociedades a partir de um saber partilhado fundador que Ihe garante a força expressiva e sua perenidade. É verdade que, muitas vezes, a história de seu nascedouro se perde ao longo dos anos, mas aquilo que a expressão representa para o grupo de partilha costuma ser perpetuado mesmo assim. O ditado em questão, ainda que despregado de sua origem, sentencia aquilo a que se refere como fato consumado, irreversível, sem solução. Se aplicado à formação do leitor - não só a do leitor letrado, mas a do 
cidadão inserido em sociedade -, o ditado pode significar, como muitos teóricos defendem, que os saberes adquiridos na fase inicial de socialização (neste caso, por meio da Literatura) são internalizados de tal maneira que imprimirão no indivíduo sua força identitária e coercitiva (quase) imutável. Ainda que, em uma segunda fase, o ser social possa adquirir a criticidade necessária para refutar algumas "certezas" e comportamentos, muito do que o marcou nesse primeiro estágio de experiência com o mundo e com os outros servirá como direção para seu desenvolvimento pessoal o resto da vida. A irreversibilidade expressa pelo ditado, nesse ponto, encontra eco.

A socialização, naturalmente, é muito variável de sociedade para sociedade, mas nela a linguagem assume como que um estatuto universal (transcultural): a sua aprendizagem é concomitante à inculcação de esquemas interpretativos e emocionais com valor institucional que, ao serem incorporados pelos indivíduos, passam a funcionar como uma espécie de guias práticos para orientação prospectiva. Por este motivo, para a criança, a realidade interiorizada durante a sua socialização impõe-se como inevitável, com um estatuto obrigatório e indiscutível: esta é a forma concreta do seu primeiro acesso à realidade, a qual, para a criança, se confunde com o próprio mundo (não se trata de um mundo, ou apenas uma parte dele). (ESTEVES, 2016, p.75-76) 
A "inculcação de esquemas interpretativos e emocionais com valor institucional" que "passam a funcionar como guias práticos para orientação prospectiva" (grifos nossos) de que trata Esteves (2016, p. 75-76) diz respeito à importância (que deve ser) atribuída à linguagem na formação dos indivíduos. E isso se intensifica em relação à linguagem das Artes, tão mais afeita à sensibilização humana. Os bens culturais (em sentido amplo) ofertados às crianças, nessa perspectiva, podem ser vistos como referência para sua inserção social e seu posicionamento mais "conformado", ou mais "transformador" diante da realidade. Após a fase inicial de socialização, "Inês é morta", isto é, impressões, gostos, modos de agir já estão internalizados profundamente no indivíduo. Então, que o legado dessa fase se preste a um direcionamento da ordem social voltado para o questionamento, para a tolerância e para o afeto.

Em convergência com esse aspecto sobre o caráter de "guia prático de orientação prospectiva" internalizado na fase inicial de socialização - que também se confere à Literatura cujo destino preferencial é a infância -, é preciso considerar "a criança que lê em nós" a cada narrativa romanesca com a qual nos deparamos na idade adulta, como explica Jouve. A "regrediência" operada nas leituras provoca no leitor adulto 
o acionamento de memórias profundas "ao acordar o eu imaginário, normalmente adormecido no adulto acordado" (2012, p.115): "Nossas crenças infantis, reativadas em certas condições (entre elas a situação de leitura), subentendem nossas crenças de adultos": "Ler, de certa forma, é reencontrar crenças e, portanto, as sensações da infância. A leitura, que outrora ofereceu para nosso imaginário um universo sem fim, ressuscita esse passado cada vez que, nostálgicos, lemos uma história" (2012, p.117). Em outras palavras, a leitura que se faz na infância não só influi na orientação dos esquemas interpretativos e emocionais, mas, para além do que é institucional, também recheia nossa memória de experiências simbólicas e afetivas bastante pessoais com as quais vamos lidar para sempre. Outra vez, se "agora Inês é morta", que nossa memória também esteja repleta de afetos.

Essas constatações podem ser comprovadas com a história que deu origem ao nosso ditado-mote, revelando um pouco do poder que as narrativas têm para moldar perspectivas sociais e nos afetar intimamente. Trata-se de Inês de Castro, "Que depois de ser morta foi rainha" (CAMÕES, 1957, p.90), contada já em Os Lusíadas, vista como símbolo da força do amor em Portugal - e, por herança, também no Brasil. No 
posfácio da versão brasileira intitulada Inês, de Roger Mello e Mariana Massarani (2015), assim a história é sintetizada por Lilia Shwarcz:

Numa época em que não existia amor por escolha, ainda mais no mundo da monarquia, os dois foram obrigados a manter uma paixão escondida, tiveram quatro filhos $\mathrm{e}$ mesmo com a morte da rainha não puderam oficializar sua relação. Para piorar o que já era ruim, Inês foi morta a mando de d. Afonso IV, rei de Portugal e teoricamente o sogro de nossa heroína. Sem encontrar consolo, d. Pedro I, anos depois, e após a morte do pai, traz sua esposa de volta, oficializa o casamento e faz com que todos participem de um beija-mão com a rainha morta. Essa história de um amor impossível inundou a imaginação do povo, a ponto de acreditarse, na época, que as lágrimas e o sangue de Inês teriam banhado o rio Mondego, levando à criação de uma Fonte das Lágrimas, onde uma alga vermelha insiste, teimosa, como o sacrifício de Inês.

(MELLO; MASSARANI, 2015)

A expressão "Agora Inês é morta" reencontra, mais uma vez, nessa nova edição da história, sua origem registrada em mais um bem cultural dos dias de hoje e faz ecoar nas novas gerações um episódio de amor inesquecível, que marca nossa herança lusitana e orienta, em certa medida, uma maneira de entender e valorizar esse sentimento. Uma narrativa forte e muito emocionante a respeito de um amor impossível; de 
uma época em que não era permitido amar com liberdade de escolha; de relações familiares e afetivas que priorizam valores políticos; de uma dor profunda, com muito impacto social. Essa versão brasileira tem por narradora uma criança, Beatriz, uma das filhas do rei apaixonado, que conta, de seu ponto de vista, a terrível e impressionante história de Inês - e do sofrimento de seu pai, da morte daquela que era sua mãe e da violência contra sua família. A perenidade da narrativa ganha força com as novas edições (fato que colabora para mantê-la viva no imaginário popular), que continuam a valorizar o amor romântico, ainda tão presente e atual na cultura dos dois países. Por outro lado, a temática do amor impossível apresentada pela menina traz adjacentes temas fraturantes (RAMOS, 2011), como o da morte - de uma mãe -, da violência contra a família, da orfandade, da misoginia, das diferenças sociais.

Um aspecto relevante para a análise aqui proposta diz respeito ao fato de que o tratamento do discurso amoroso como perspectiva investigativa parece ofuscado por parte das pesquisas em geral, refletindo o obscurantismo a que esse tipo específico de discurso parece ter sido relegado. Em tempos de (urgente) valorização da análise crítica, da compreensão antropológica e sociológica das relações 
humanas - sobretudo as de poder e manipulação das massas -, da defesa das minorias sociais e da resistência aos preconceitos, apagam-se o discurso amoroso e sua importância dos movimentos de resistência/reexistência, esquecendo-se de que é ele fator de mobilização, de conscientização sensível e de humanização. Em cada expressão de empatia, tolerância, valorização do coletivo, o discurso amoroso atua como base fecunda - não romântica, mas, de complacência, respeito, união, agregação.

Como em Barthes (1988), em seu Fragmentos de um discurso amoroso, esta reflexão tem como justificativa a necessidade de se delimitar um lugar de afirmação para o discurso amoroso, "completamente abandonado pelas linguagens circunvizinhas: ou ignorado, depreciado, ironizado por elas, excluído não somente do poder, mas também de seus mecanismos (ciências, conhecimentos, artes)" (BARTHES, 1988, prefácio). Entretanto, é preciso enfatizar o aspecto que diferencia nosso propósito daquele de Barthes: o discurso amoroso de que nos ocuparemos diz respeito às formas de dizer e implicar o amor (em sentido geral); o amor como resistência a uma ordem social altamente exclusiva; amor como respeito ao próximo, empatia, tolerância, convívio saudável, lembrança de nossa 
(melhor) humanidade. É o discurso amoroso que permeia nosso imaginário sociodiscursivo que nos interessa - em uma perspectiva que também pode incluir, mas que, sobretudo, ultrapassa o amor-paixão.

Como exemplo, citamos $O$ livro do Pedro (Maria dos 7 aos 8 anos), de Marcela Bacelar (2008), uma narrativa cujo propósito é não só o de incluir no universo da literatura Infantil temas considerados quase proibidos como 0 da homoparentalidade, mas, sobretudo, de conseguir, de "forma sutil e sensível", "normalizar" a situação, ao selecionar "uma família constituída por dois pais para tratar a questão central da importância dos afetos" (RAMOS, 2011, p.202). Enfatiza-se, aqui, o fato de a questão central dessa narrativa ser a importância dos afetos, e não a aceitação da homoparentalidade, embora esse tema tão relevante esteja presente no texto de forma "periférica". O tratamento dado a esses tópicos é um caso de discurso amoroso explorado em um conto ilustrado para crianças. Trata-se de uma história de amor que ultrapassa o limite do romantismo e alcança o laço familiar, o respeito e a tolerância. É esse tratamento dado ao discurso amoroso que nos interessa. 


\section{PATEMIZAÇAO E PROJEÇÃO PERSUASIVA EM CONTOS ILUSTRADOS}

Para abordar o discurso amoroso, parece pertinente atentar para o conceito de patemização, partindo da Semiolinguística, uma teoria de análise do discurso, mas também focalizando processos semióticos icônicos, na esteira de Peirce (2001; SANTAELLA; NÖTH, 2005), muito propícios para a exacerbação de sentimentos.

De acordo com a Semiolinguística, (CHARAUDEAU, 2007), a patemização consiste na utilização de recursos expressivos com a intenção de provocar uma reação emocional no interlocutor. Trata-se de um tipo de visada discursiva, isto é, de uma "programação" textual apropriada para o desencadeamento de emoções baseadas em representações sociais. Seria um tipo de estratégia vinculada ao pertencimento social, à partilha de saberes relacionados à reação emocional. Não se trata da expressão objetiva das emoções por meio de palavras, ou de gestos, ou de imagens: dizer “indignação", ou "paixão", ou referir-se ao pânico por meio de uma expressão fisionômica não implica necessariamente o desencadeamento do sentimento no outro. Já palavras como "bala perdida", "feminicídio", ou a imagem de um uniforme escolar ensanguentado, ou de uma criança afogada na beira 
da praia, ligadas ao contexto em que são utilizadas, podem ser boas candidatas a suscitar medos, horrores, tristezas, por serem expressões previamente vinculadas a reações emocionais que se partilham socialmente.

Além disso, ainda segundo Charaudeau, é importante observar que a patemização insere-se em uma problemática de influência: "Como tocar o outro é o objetivo que o sujeito falante pode ter para fazer com que este outro não faça reflexões sobre a fala em questão e se deixe levar pelos movimentos de seus afetos" (CHARAUDEAU, 2007, p.245). A fim de se obter a efetiva reação emocional pretendida, é preciso buscar um modo favorável de organizar a descrição do mundo; um modo de garantido reconhecimento pelo grupo de partilha.

Além da inserção de expressões potencialmente patêmicas (oriundas de quaisquer meios semiológicos), atenta-se igualmente para um tipo de processamento essencialmente semiótico altamente oportuno para a exacerbação de qualidades (sentimentos, percepções, atributos): a iconicidade. Para uma delimitação bastante sucinta, pode-se dizer que, segundo a semiótica peirciana, se trata de um mecanismo significativo baseado na semelhança. Pode ser observada na interioridade do signo, isto é, em sua 
constituição; entre signo e objeto. Isso ocorre nas imagens, nas quais o significante se parece com aquilo que significa, ou ainda nas onomatopeias, quando o conjunto sonoro se assemelha àquilo que indica. Também pode ser observada na relação entre os signos, principalmente nas metáforas, nas intertextualidades e intericonicidades. É possível ser igualmente observada, por exemplo, na identificação do sujeito interpretante com o destinatário programado pelo texto: nessa fusão, um leitor, vendo-se semelhante ao destinatário, adere ao projeto textual e se identifica de tal forma que se abre ao texto e às suas pulsões.

A patemização, seja na perspectiva discursiva, seja na semiótica, torna-se fundamental para o desenvolvimento de uma competência fruitiva (FERES, 2011), aquela que dota o indivíduo de habilidades para sentir o texto e por meio dele. Tanto no âmbito estético, quanto no emocionalsensorial-mnemônico, o trabalho com a criação de textos cuja intencionalidade se direciona primordialmente para a fruição depende, também, de uma recepção "educada" para o sentimento de uma superfície textual saborosa, opaca, para ser apreendida pelos sentidos; de uma textualidade aberta e cheia de lacunas a serem preenchidas na leitura com a subjetividade do sujeito e com a memória, que ele carrega, do mundo e das pessoas; de uma interação pressuposta 
entre leitor e texto, que o leve a inferências intelectivas e afetivas, além de colocá-lo na posição de aderência à proposta textual.

Por isso, a aposta em contos ilustrados narrativos, a partir da mediação, realizada, por um lado, pelo texto mesmo, aproximando a criança e o mundo, e, por outro, pelo adulto mediador, que, quase sempre, é o "coleitor" que salienta aspectos do texto e das memórias, a fim de ampliar a experiência significativa e afetiva. Dessa maneira, as narrativas propiciam a projeção persuasiva, já que operam na projeção do leitor com o texto, ao fazê-lo identificar-se com algum personagem, ou com a cena narrada, tomando parte nas ações e nos sentimentos. Assim, pode sentirse tocado em sua emoção e em sua experiência estética e ética e, fruindo, viver uma transformação interna - quase sempre inconsciente. Mais do que em uma argumentação direta, plena de raciocínios abstratos e imposições, em uma narração, o leitor/espectador engajado é alvo de uma adesão não só em relação às ações contadas no texto, mas às decisões e aos sentimentos vividos ficcionalmente. A persuasão se dá, portanto, no terreno do afeto, da vivência interna, da identificação do sujeito-leitor com aquela proposta de mundo. De uma vez só, é possível fazer saber, fazer sentir e fazer crer. 


\section{A HISTÓRIA DE INÊS DE CASTRO: MARCAS DE FORMAÇÃO E AFETO}

Na análise dos contos ilustrados A lenda de Pedro e Inês, de Margarida Almeida e Margarida Lisboa Pina (Kadernu, 2014), e Inês, de Roger Mello e Mariana Massarani (Companhia das Letrinhas, 2015), serão abordadas expressões do amor e visadas amorosas, a partir das quais o amor é inferido, não dito.

As obras selecionadas para esta análise são versões de uma mesma história, então, alguns dados comuns podem ser assim condensados: trata-se da história de amor - e de tragédia - vivida por Pedro, herdeiro do reino português, e por Inês, aia de Constança, sua mulher. Quando viúvo, Pedro quis torná-la rainha, D. Afonso IV, pai de Pedro, mandou assassiná-la cruelmente. Como vingança, Pedro coroou-a mesmo morta e obrigou o reino a beijar-lhe a mão.

Na versão portuguesa de Almeida e Pina (2014), um dado peculiar: o livro é (também) vendido no hotel Dona Inês, em Coimbra, onde a história de Pedro e Inês ainda repercute como curiosidade turística. É uma versão bilíngue (português e inglês), bem condensada, tratada como lenda - o que reafirma sua natureza ficcional e mitológica para aquele grupo social. 


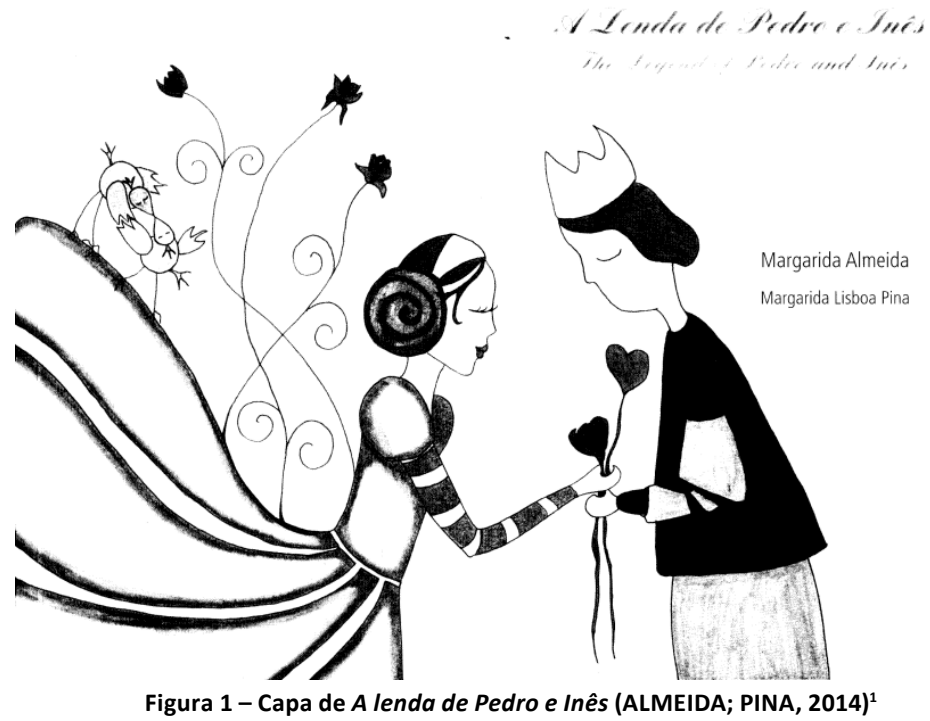

A capa destaca uma das imagens do interior do livro, mostrando o romance entre os protagonistas, corroborado por outros símbolos, como passarinhos unidos pelos bicos; a troca, entre os amantes, de uma rosa e um coração; a delicadeza e feminilidade de Inês em um vestido azul claro, lábios vermelhos e cílios longos; a realeza de Pedro identificada pelo coroa. O fundo das ilustrações é sempre branco, deixando a cena representada em evidência. O traço é infantil e as imagens, um tanto previsíveis e coloridas.

1 As ilustrações de A lenda de Pedro e Inês (ALMEIDA; PINA, 2014) são de autoria de Margarida Lisboa Pina. 


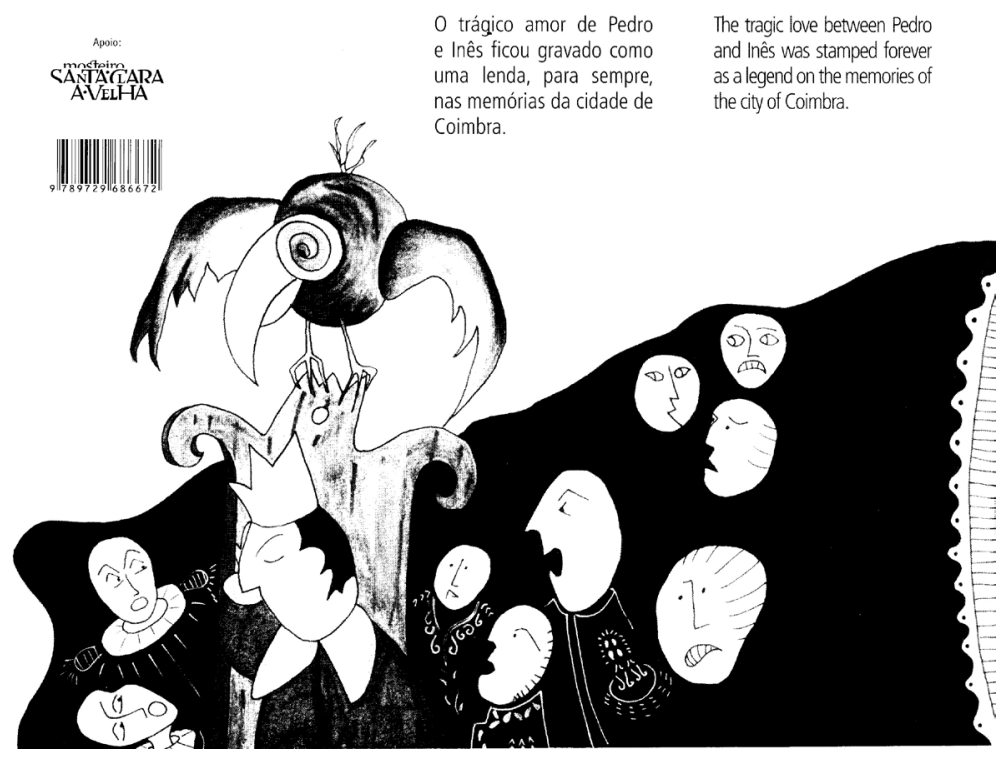

Figura 2 - Contracapa de A lenda de Pedro e Inês (ALMEIDA; PINA, 2014)

Na contracapa, também em uma cena extraída do interior do livro, o rei é ilustrado com um gesto de preocupação, com a mão direita na cabeça. Um corvo se empoleira em seu trono e, em um fundo preto, rostos com expressão acusatória olham para ele. Em outras palavras, a apresentação externa da narrativa já destaca o amor romântico e o antagonismo do rei. Ainda na contracapa, diz-se: "O trágico amor de Pedro e Inês ficou gravado como uma lenda, para sempre, nas memórias da cidade de Coimbra" (ALMEIDA; PINA, 2014). As folhas de guarda contêm um coração vermelho ao centro, com passarinhos que se beijam, como na capa. 
No interior, estão separadas em páginas distintas a parcela verbal e a imagética. Não há páginas duplas e a ilustração sangra as páginas em que aparece. A narração em 3 a pessoa e a abertura temporal com "No tempo dos reis" garantem distanciamento em relação ao relato. Iniciada com uma explicação acerca do casamento arranjado entre Pedro e Constança, a ilustração correlata na página à direita mostra homens apontando mapas e brasões para o rei, indicando a aliança política obtida com o casamento. Como já dito, a narrativa é bem condensada e objetiva. Nas páginas que seguem à abertura, à esquerda, a chegada de Inês é mostrada e, à direita, contada, com a devida descrição da personagem:

O príncipe D. Pedro, filho de D. Afonso IV, rei de Portugal, casou com D. Constança, uma nobre castelhana.

Inês era uma jovem aia, extremamente bela, que chegou à corte portuguesa no séquito de D. Constança. Assim que a viu o príncipe ficou imediatamente rendido aos seus encantos femininos.

Esse amor à primeira vista foi tão evidente que todos na corte sabiam que Pedro e Inês estavam apaixonados um pelo outro. (ALMEIDA; PINA, 2014, s/p.)

A esperança de afastamento de Inês e Pedro é nutrida por Constança quando tem o primeiro filho e convida Inês para madrinha. A ilustração que acompanha o relato traz, mais uma vez, a presença do corvo, como metáfora da desgraça 
anunciada, mas também outra, mais baseada no senso comum: um coração partido ao meio, amarrado por uma corda que está quase sendo cortada por uma tesoura. Abaixo desses elementos, Constança e Inês dividem a atenção com o bebê.

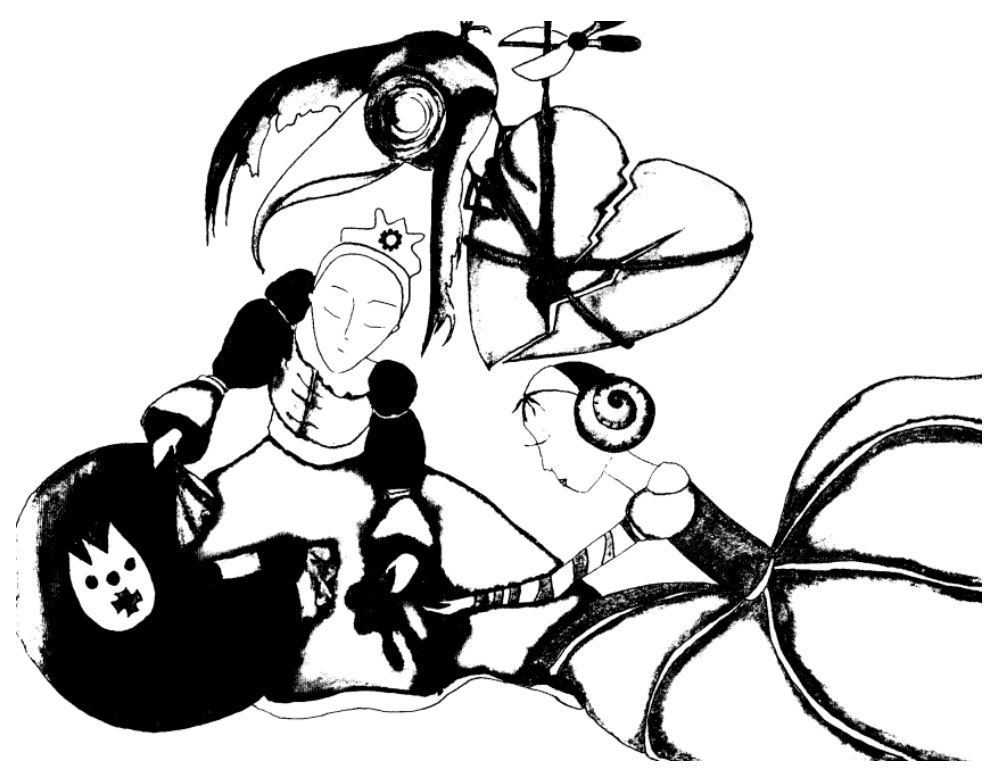

Figura 3 - Constança convida Inês para madrinha de seu primogênito. (ALMEIDA; PINA, 2014, s/p.)

O bebê morre, assim como Constança, após o parto de seu segundo varão. A pressão contra Inês cresce no reino. Ao saber que Pedro pretende se casar com ela, D. Afonso manda matá-la. Inês é assassinada diante de seus filhos. Após a morte do rei, Pedro manda matar os carrascos de Inês e trasladar seu corpo para o Mosteiro de Alcobaça, para um túmulo digno de uma rainha: 
Aquela paixão impressionou bastante as gentes da época. Dizia-se que o rei, num ato de loucura extrema, mandou sentar o corpo de Inês num trono e colocou-Ihe uma coroa de rainha na cabeça. Depois, obrigou os súbtidos a beijar as falanges descarnadas do cadáver em sinal de reconhecimento de sua realeza. (ALMEIDA; PINA, 2014, s/p.)

Nesse caso, a representação do beija-mão da rainha na ilustração não deixa transparecer marcas da morte; apenas, na parte verbal, há referência aos beijos nas falanges descarnadas de Inês. A história é finalizada com a menção aos túmulos dos reis, dispostos um em frente ao outro, para o reencontro na ressurreição.

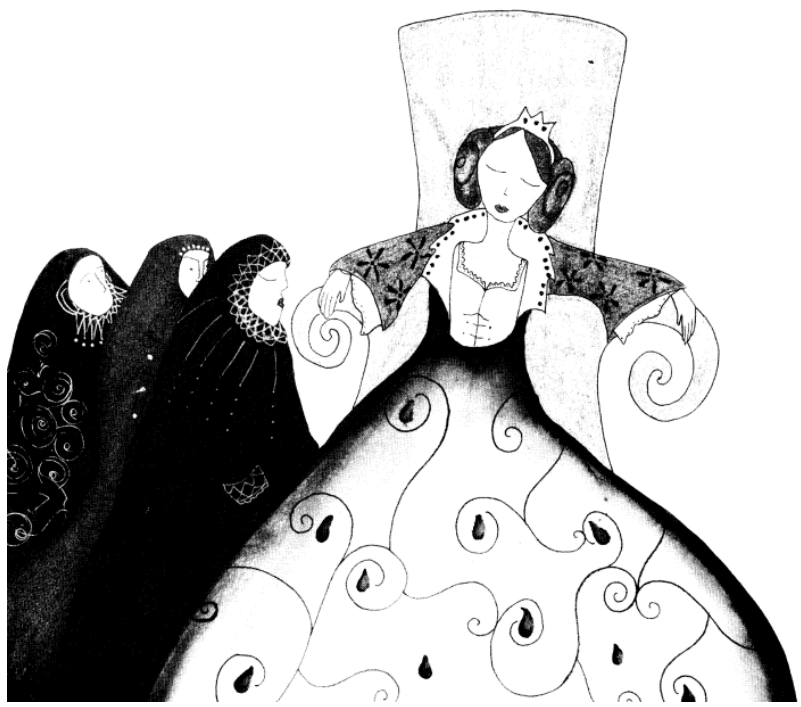

Figura 4 - 0 beija-mão de Inês (ALMEIDA; PINA, 2014, s/p) 
Destaca-se, nessa versão, uma maior objetividade e condensação da história, narrada em terceira pessoa e ambientada em tempos remotos, além da caracterização como lenda, garantindo-Ihe o distanciamento necessário em relação à trágica história, inclusive por causa do grau de ficcionalidade atribuído, além de sua aura fantástica. A tessitura verbal é igualmente objetiva e baseada no senso comum, mesmo nas metáforas. O amor e a paixão são nomeados ("esse amor à primeira vista", "estavam apaixonados um pelo outro", "a paixão do marido e da aia", "a paixão de Pedro pela aia") e sua representação imagética, em geral, também é meramente identificadora. Os elementos patêmicos não são muito numerosos, nem muito expressivos. A ilustração, que costuma ser espaço para implicitação de sentidos e ideologias, é quase toda igualmente objetiva, atuando semanticamente em relação ao repertório de costumes de uma época remota. As metáforas visuais, como já mencionado, são rasas, baseadas em clichês.

No quadro a seguir, destacam-se as estratégias mencionadas: 
A LENDA DE PEDRO E INÊS (ALMEIDA; PINA, 2014)

\begin{tabular}{|c|c|c|}
\hline FAZER SABER & FAZER SENTIR & FAZER CRER \\
\hline $\begin{array}{l}\text { - } \quad \text { Narrativa em 3ã pessoa. } \\
\text { - } \quad \text { Distanciamento no tempo. } \\
\text { - } \quad \text { Ficcionalidade acentuada pela } \\
\text { categorização como lenda. } \\
\text { - } \quad \text { Referenciação verbo-visual } \\
\text { objetiva, com identificação por } \\
\text { nomeação e por imagens } \\
\text { estereotipadas. } \\
\text { - } \text { Relação palavra-imagem } \\
\text { predominantemente } \\
\text { "redundante" semanticamente. } \\
\text { - Repertório imagético } \\
\text { relacionado à "época dos reis e } \\
\text { rainhas", indumentárias, } \\
\text { ambientes domésticos, hábitos } \\
\text { de vida. }\end{array}$ & $\begin{array}{l}\text { - Ilustrações } \\
\text { coloridas e } \\
\text { expressivas das } \\
\text { cenas principais, } \\
\text { com fundo } \\
\text { branco; imagens } \\
\text { convergentes com } \\
\text { a parcela verbal } \\
\text { no que respeita à } \\
\text { expressão dos } \\
\text { sentimentos pelas } \\
\text { fisionomias e pela } \\
\text { gestualidade. } \\
\text { Metáforas visuais } \\
\text { baseadas no } \\
\text { senso comum. }\end{array}$ & $\begin{array}{l}\text { - Tema central: o amor } \\
\text { deve ser livre; o amor- } \\
\text { paixão é algo louvável; o } \\
\text { amor à primeira vista é } \\
\text { muito romântico; o } \\
\text { amor vence a morte; o } \\
\text { amor é mais importante } \\
\text { do que valores sociais e } \\
\text { políticos. } \\
\text { - Temas secundários: } \\
\text { vingança justificada pela } \\
\text { dor e pela injustiça; } \\
\text { valores sociais e políticos } \\
\text { se sobrepõem aos } \\
\text { valores humanos; } \\
\text { desvalorização da } \\
\text { mulher na sociedade. }\end{array}$ \\
\hline
\end{tabular}

Quadro 1 - Estratégias em A lenda de Pedro e Inês

Já na versão brasileira de Mello e Massarani (2015), o vermelho do fundo na capa e na contracapa já antecipa, simbolicamente, o teor apaixonado e trágico-violento da narrativa. O destaque, nesse espaço externo, é a cena do beija-mão da rainha morta, com ênfase na interminável fila de súditos que esperam para venerá-la. O ambiente "real" se faz representar na imagem por meio da indumentária e dos comportamentos, das relações entre as personagens coadjuvantes que ali se apresentam. O título "Inês" já aponta 
para a centralidade da personagem - e não para a paixão entre ela e Pedro.

Na contracapa, explica Schwarcz (Apud MELLO; MASSARANI, 2015): “Toda vez que queremos dar uma coisa por acabada dizemos: 'Inês é morta'. Roger Mello e Maria Massarani mostram que, ao contrário, a rainha Inês vive em cada um de nós e em cada detalhe deste poema em forma de livro". Essa explicação comprova, além da poeticidade constitutiva da obra, a centralidade de Inês na versão de Mello e Massarani: "Inês vive em cada um de nós", habitando nosso imaginário e mexendo com nossa empatia em relação a uma mulher delicada e amorosa, preocupada com os filhos e silenciada pelos poderosos.

Na ilustração, inúmeros detalhes interessam aos olhos: os personagens na fila imensa conversam entre si, alguns carregam cestos de alimentos nas cabeças, as mulheres se vestem totalmente de preto e têm a cabeça coberta, ou usam chapéus estranhos, com véus esvoaçantes; há patos, carneiros, porco, cachorro, cavalos, boi, coelho e gato misturados às pessoas; adultos, velhos, jovens, uma grávida, serviçais e nobres (posições sociais indicadas pelas roupas, chapéus, turbantes, véus); um velho de barba longa está na fila em cima de sua cama, outro, cochila em sua cadeira, e outra pessoa espreita através de uma tenda. 
A fila iniciada na exterioridade do livro se estende também às folhas de guarda onde, finalmente, chega o momento de cumprimentar os reis e beijar a mão da rainha morta. No interior do livro, porém, o fundo das páginas apresenta outras cores, mais atenuadas (embora o vermelho ainda apareça nas cenas de encontro entre os amantes, na cena em que o príncipe entra em desacordo com o pai e na cena do beija-mão). O traço infantil delineia não só as personagens, mas, inclusive, a moldura florida, com passarinhos e um caracol, que abre a narrativa com as seguintes palavras já impregnadas de poesia: "Quando eles se conheceram, eu andava escondida no meio de outras coisas. Curva de brisa, alga vermelha, briga de passarinho. Eu ainda não era uma vez" (MELLO; MASSARANI, 2015, s/p.). É a filha de Inês e Pedro, Beatriz, que assume, como narradora-testemunha, o relato dos acontecimentos.

Ao longo do texto, o processo de referenciação, introduzindo objetos de discurso no texto, categorizandoos e recategorizando-os (KOCH; ELIAS, 2016), utiliza recursos poéticos variados, que procuraremos exemplificar minimamente. As figuras ora ganham contorno preto e preenchimento branco, como Inês e Pedro em seu primeiro encontro, ora ganham cores, como a roupa do rei na mesma 
cena, formada por pequenos quadrados pretos e roxos, além da cruz amarela no peito. As expressões fisionômicas são muito significativas; olhares de soslaio revelam interesse, mas também vigilância.

Beatriz apresenta Pedro, "meu pai", e Inês, "essa moça que sorriu quando o príncipe fez a carruagem parar" (MELLO; MASSARANI, 2015, s/p.): “Pedro sorriu sem pressa. O cavalo de Pedro sorriu pro capim. Briga de brisa, curva de passarinho. Algo vermelha. Inês, minha mãe". Além do sentimento indicado pelos sorrisos, inclusive o do cavalo, que "sorriu pro capim" (demonstrando certo constrangimento e detecção do amor à primeira vista), a expressão de abertura que, iconicamente, representa a harmonia natural das coisas que ainda não são ("Curva de brisa, alga vermelha, briga de passarinho") se embaralha como os sentidos de quem se apaixona repentinamente: "Briga de brisa, curva de passarinho. Algo vermelha". Mais tarde, de novo essa expressão se transmuta quando Dom Afonso, para separar Inês de Pedro, manda-a para um castelo em Castela: "onde nem brisa nem passarinho chegavam. Briga vermelha, curva de alga". De maneira poética, a emoção que suplanta a razão é concretizada na confusão de palavras, expressando, por meio da iconicidade, a desordem emocional. A visada patêmica 
aqui já pode ser flagrada, dependente da inferência acerca das emoções (que não são nomeadas, mas metaforizadas dessa maneira e de outras, ao longo da narrativa).

Outro recurso verbal ligado à referenciação e à poesia é a utilização de vários epítetos, comuns em relação aos nobres e aos poderosos, que aqui caracterizam a mudança de Pedro: "Pedro, o Desobediente"; "Pedro, o Confuso"; "Pedro, o Mentiroso"; "Pedro, o Apressado"; "Pedro, o Resoluto"; "Pedro, o Cruel"; "Pedro, o Cru"; "Pedro isso"; "Pedro aquilo"; "Pedro, o Vingativo"; "Pedro, o Justo". São epítetos que marcam a fragilidade humana, a variedade de possíveis sentimentos e estados de espírito que se alternam ao sabor dos acontecimentos. Já Inês é referida como "a recém-chegada", "a ama da princesa", "a rainha morta".

Já a referenciação pela imagem, desde a capa, como vimos, oferece múltiplos sentidos e detalhes. O repertório imagético relacionado à realeza ali se confirma e se perpetua, mas também oferece algumas subversões, como a representação de Beatriz descalça; os cabelos volumosos de Inês, adornados com florezinhas; as árvores secas que se curvam tanto quanto as pessoas que acompanham o enterro de Constança; a única janela colorida de laranja no alto da torre sem cor, onde Inês fora confinada. O amor familiar 
entre Inês e os filhos - Afonsinho, Beatriz, João e Dinis - é expresso por um abraço quase coletivo entre eles, enquanto a mãe joga um bebê para o alto e um rapazote carrega uma flor na mão e oferece uma pera para ela.

A cena do assassinato de Inês é a única no livro que se espraia em uma página dupla, que também sangra. O fundo vermelho, como já se disse, colore a violência do ocorrido. Os algozes, nomeados na parte verbal, imageticamente são indicados por metonímia: na ilustração, aparece apenas a parte inferior de seus corpos, botas, espada, adaga, mantos bordados. No centro da imagem, Inês aparece trespassada pela adaga. "Agora Inês é morta."

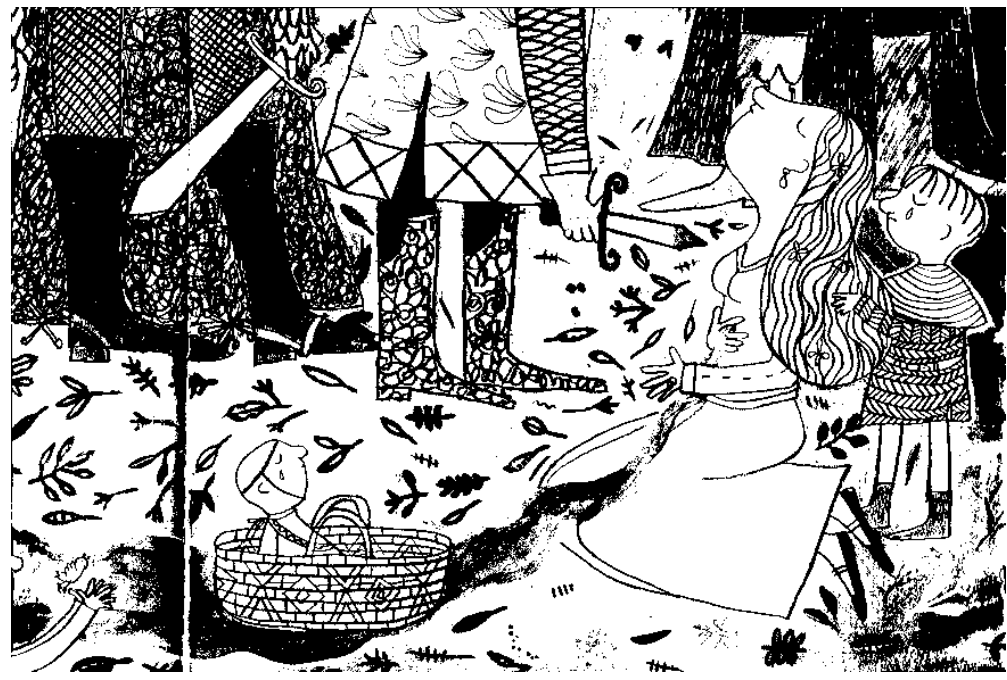

Figura 5 - Morte de Inês (MELLO; MASSARANI, 2015, s/p.) ${ }^{2}$

2 As ilustrações de Inês (MELLO; MASSARANI, 2015) são de autoria de Mariana Massarani. 
A ideia de desenterrar Inês é categorizada na narrativa como uma vingança de Pedro. Ainda assim, Pedro, pelo ponto de vista da narradora, guarda sua sensibilidade: "Vejam só o corpo de Inês seguindo num cortejo pra Coimbra. Pedro olha sua rainha morta. Ele sorri Beatriz e eu sorrio Pedro" (MELLO; MASSARANI, 2015, s/p.). A cumplicidade e o carinho entre pai e filha também aparecem mais adiante: "Sempre que eu fazia um carinho no bigode preto de Pedro, acabava segurando seu sorriso" (MELLO; MASSARANI, 2015, s/p.). Mais uma vez, apresenta-se o amor sem nomeá-lo.

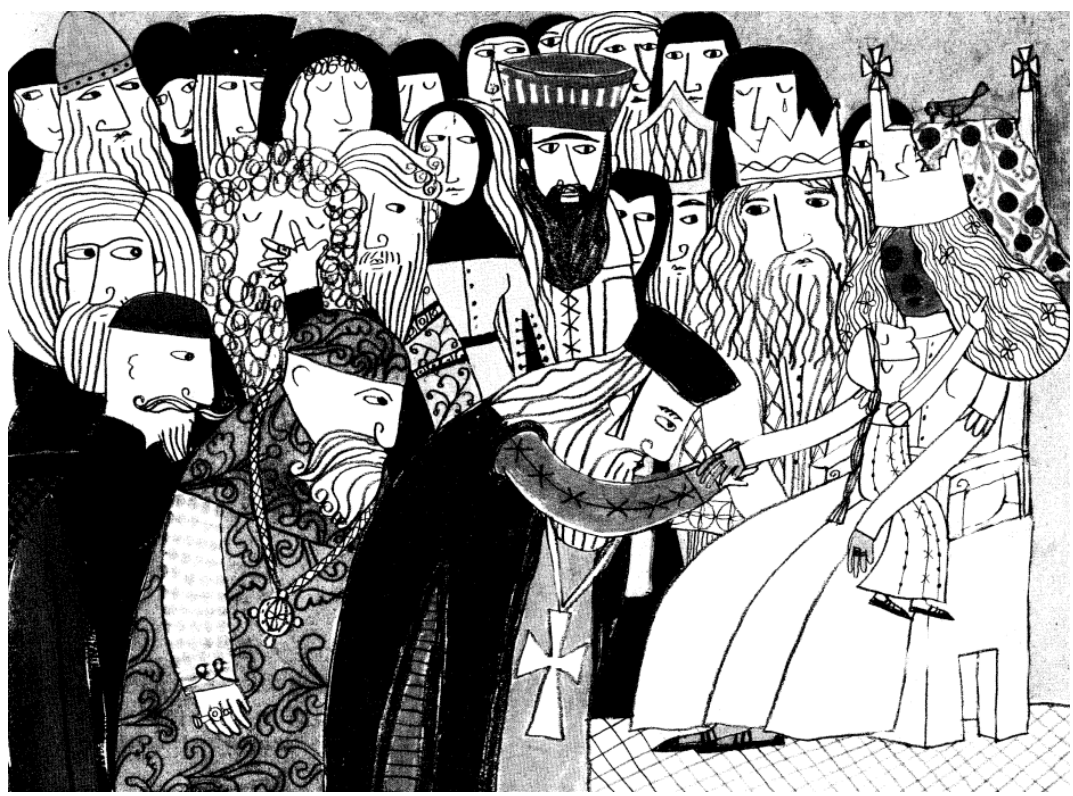

Figura 6 - O beija-mão da rainha morta (MELLO; MASSARANI, 2015, s/p.) 
A cena do beija-mão, nessa versão, mostra semblantes consternados e uma rainha morta roxa, coroada, no trono, enfeitada com as mesmas florezinhas nos cabelos. Estão todos aglomerados, de olhos fechados, ou expressando tristeza, comiseração, desconfianças, acusação. Beatriz está sentada no colo da mãe, mexendo em seus cabelos e minimizando, com o gesto, do terror da morte.

$\mathrm{Na}$ parcela verbal, reitera-se a desconfiança acerca do casamento entre Pedro e Inês. Em diálogos bastante sucintos, infere-se a destreza de Pedro para realizar sua vingança.

O cardeal:

- Vossa Majestade Pedro, quando foi o casamento?

- Eu não lembro o dia certo.

E o cardeal teve tempo de beijar a mão da rainha morta.

$O$ duque:

- Vossa Majestade Pedro, onde foi o casamento?

- Só pra você eu não digo.

O conde:

- Vossa Majestade Pedro, alguém viu o casamento?

- O capelão.

- Vossa Majestade?

- Agora não.

- Vossa Majestade?

Agora chega! 
O marquês, o visconde e o barão, todos tiveram que beijar a mão da rainha morta.

Na noite em que foi coroada, Inês soprou um pouco de brisa debaixo de cada janela.

Eu me ajeitei no colo dela, passei a mão no seu cabelo, endireitei sua coroa. (MELLO; MASSARANI, 2015, s/p)

A perspectiva da filha adoça a narrativa, colocando em pauta não só a trágica história de amor (e vingança), mas também a relação afetiva da menina com a família, com destaque ao cuidado que revela ter com o pai. $O$ que se mostra em primeiro plano nessa versão, portanto, difere da anterior. Agora, Inês, mãe da menina, é mostrada como uma lembrança. A relação de afeto em primeiro plano é a da menina, órfã de mãe, com o pai, viúvo. O silenciamento da mulher também é mostrado, tanto no apagamento de Constança, simples princesa que se casou com o pai de Beatriz, quanto na falta de escolha de Inês, primeiro afastada em um castelo distante, depois, morta diante das crianças, mesmo tendo implorado: "Mas vocês me ameaçam na frente dos filhos do seu rei?" (MELLO; MASSARANI, 2015, s/p.). Além do amor evocado pelos recursos expressivos, infere-se, emocionalmente, a indignação daquela injustiça - aos olhos de quem acredita no amor acima das convenções e acordos políticos. 
Destacam-se as seguintes estratégias discursivas nessa versão da história:

\begin{tabular}{|c|c|c|}
\hline \multicolumn{3}{|c|}{ INÊS (MELLO; MASSARANI, 2015) } \\
\hline FAZER SABER & FAZER SENTIR & FAZER CRER \\
\hline $\begin{array}{l}\text { - } \quad \text { Narrativa em primeira pessoa; } \\
\text { narradora-personagem-testemunha. } \\
\text { - } \quad \text { nempo da narrativa aproximada ao da } \\
\text { marcas de um tempo histórico } \\
\text { distante. } \\
\text { - Condensação de fatos, com algumas } \\
\text { descrições e diálogos. } \\
\text { - } \text { Referenciação verbo-visual criativa, } \\
\text { metafórica e implicitadora. } \\
\text { - Ficcionalidade atenuada pela } \\
\text { subjetividade do relato. } \\
\text { Relação palavra-imagem } \\
\text { complementar, com importante } \\
\text { detalhamento visual das cenas. } \\
\text { Repertório imagético relacionado à } \\
\text { "época dos reis e rainhas" reiterado } \\
\text { pelas indumentárias, pelos ambientes } \\
\text { domésticos e hábitos de vida. }\end{array}$ & $\begin{array}{l}\text { - Parcela verbal poética, } \\
\text { com metáforas e outros } \\
\text { recursos estilísticos. } \\
\text { - Subjetividade da } \\
\text { personagem-narradora- } \\
\text { testemunha como dado } \\
\text { de identificação/empatia } \\
\text { para o leitor. } \\
\text { - Parcela imagética rica } \\
\text { em detalhes, } \\
\text { acrescentando dados e } \\
\text { expressividade. } \\
\text { - Cores e ilustrações com } \\
\text { utilização de metonímias } \\
\text { e metáforas visuais. }\end{array}$ & $\begin{array}{l}\text { - Tema central: o amor é } \\
\text { mais importante do que } \\
\text { convenções sociais e } \\
\text { política; o amor à } \\
\text { primeira vista é muito } \\
\text { romântico. } \\
\text { - Temas secundários: o } \\
\text { amor familiar é } \\
\text { importante em } \\
\text { momentos difíceis, } \\
\text { como na morte de uma } \\
\text { mãe/esposa; vingança } \\
\text { justificada pela dor e } \\
\text { pela injustiça; pessoas } \\
\text { apresentam } \\
\text { sentimentos e reações } \\
\text { bons e maus; o } \\
\text { silenciamento da } \\
\text { mulher. }\end{array}$ \\
\hline
\end{tabular}

Quadro 2: Estratégias em Inês

\section{O MESMO (?) DISCURSO AMOROSO EM DUAS VERSÕES}

Não há melhor documento que a literatura infantil para saber a forma como a sociedade deseja ver-se a si mesma.

Teresa Colomer (2017)

O que parece possível salientar nesta breve análise é, de um lado, a força de uma narrativa impactante e sua perenidade nos imaginários de várias gerações e, de outro, o modo como cada versão apresenta uma mesma história, revestindo-a de um caráter mais ou menos poético e patêmico. 
Ambas as versões tratam do mesmo tema, que reafirma a valorização positiva do amor romântico. Ambas justificam atitudes tresloucadas como o assassinato da mulher-amantedo-príncipe por causa das alianças políticas, ou mesmo a coroação da rainha morta e o beija-mão imposto aos súditos em função da vingança e da exaltação do amor-paixão. Em termos de persuasão projetiva (isto é, da argumentação subjacente à narrativa, aproveitando o envolvimento do leitor na história), observa-se que, se a lógica argumentativa prevê uma asserção de partida, uma de chegada e uma ou mais de passagem, essas versões partem da premissa (asserção de partida) de que o amor é maior do que tudo, para chegar à conclusão de que o amor suplanta interesses políticos e convenções sociais e até a morte (asserção de chegada). Como asserções de passagem, a história apresenta o amor clandestino subvertendo a ordem social e política, além da coroação e do beija-mão após a morte da rainha. Essas ações funcionam como provas, como argumentos que incitam o leitor a aceitar a proposta como verdadeira. Em outras palavras, pode-se afirmar que ambas as versões acalentam um mesmo fazer crer.

Entretanto, há inúmeras diferenças estre as versões. A intencionalidade que subjaz A lenda de Pedro e Inês (ALMEIDA; 
PINA, 2014) privilegia o fazer saber em virtude de seu "caráter difusor de cultura", por isso a linguagem mais objetiva e condensada, distanciada pela narrativa em terceira pessoa e pela lacuna imposta pelo tempo narrado, com recursos discursivos mais brandos em relação à sensibilização, apenas voltados para o destaque da dramaticidade da trágica lenda portuguesa. Comparada à outra versão, é possível afirmar que esta é menos opaca, menos propensa à fruição estética, ou mesmo ética.

Já a intencionalidade implícita em Inês (MELLO; MASSARANI, 2015) ressalta o fazer sentir em consequência de seu caráter poético, então a linguagem mostra-se mais subjetiva, com uma narração mais engajada, em primeira pessoa, protagonizada por uma personagem-narradoracriança-filha-de-Inês-e-Pedro - posição que Ihe garante legitimidade para contar e envolvimento com o contado. O texto em si se constitui de recursos discursivos e poéticos - tanto verbais quanto imagéticos - que atraem a percepção para os detalhes, para os refinamentos, para as sensibilidades. O leitor é instado a olhar e a inferir. O ponto de vista adotado provoca a empatia do leitor e conduz seu olhar não apenas para a trágica história de amor, mas para a perspectiva da narradora, para sua relação com a família, 
para o amor dela pelo pai e do pai por ela - para o discurso amoroso que conduz a narrativa. Pode-se inclusive afirmar que, nessa versão, há outro percurso argumentativo voltado para um fazer crer ligado à premissa de que o amor fraterno ajuda a superar o sofrimento.

Em contrapartida, além das marcas de formação e de afeto mencionadas (desde os signos e suas simbologias aos recursos de implicitação de ideias e de sentimentos), observam-se nos textos outros índices igualmente relevantes, mas, quase sempre, tomados em sua estereotipia e "naturalidade", como, sobretudo, a representação da mulher, sempre silenciada e subalterna à dominação masculina. Ainda que, na versão brasileira, Inês, em um dado momento, imponha sua vontade a Pedro, dizendo onde quer morar com a família após a morte de Constança, a opressão sofrida pela mulher se concretiza em sua morte cruel diante dos filhos. Outro aspecto é a reação vingativa de Pedro, justificada pela indignação e pela injustiça. Embora recorrentes na história humana e nas narrativas ficcionais, essas versões repetem, implicitamente, a vingança justificada. É verdade que, em Inês, a profusão de emoções e de atitudes (anti) éticas, evidenciadas pelos epítetos direcionados a Pedro, também subentendem a incoerência e a fragilidade moral 
das pessoas, suscetíveis às imposições da realidade. Mesmo assim, a vingança justificada permanece como informação que continua a povoar os imaginários de nossa sociedade.

Esses são aspectos que podem ser vistos nos livros como simples relatos, ou como constatações das relações humanas, ou como evidências de temas que precisam ser questionados. Sua apresentação coadjuvante aos fatos centrais, contudo, exige do leitor uma leitura crítica. Em outras palavras, nessas narrativas, são exploradas fortes emoções, mas também valores socialmente referendados, não necessariamente impostos para perpetuação, porém naturalizados pelas convenções e axiologias.

Para finalizar, reitera-se a relevância de uma abordagem que privilegie não só a observação de recursos discursivos e poéticos que, nos textos literários em tela, contribuem para a formação dos imaginários, mas também a necessária centralidade do discurso amoroso para a socialização das novas gerações e para a sensibilização humana. Pretendese, assim, colaborar para destacar um bem cultural de importante caráter formativo, coadjuvante na construção de um mundo melhor. E mais amoroso. 


\section{REFERÊNCIAS}

ALMEIDA, Margarida; PINA, Margarida Lisboa (2014). A lenda de Pedro e Inês. Coimbra: Kadernu.

BACELAR, Marcela (2008). O livro do Pedro (Maria dos 7 aos 8 anos). Porto: Afrontamento.

BARTHES, Roland (1988). Fragmentos de um discurso amoroso. 7.ed. Rio de Janeiro: Francisco Alves.

CAMÕES, Luís de (1957). Os lusíadas. Porto: Livraria Figueirinhas.

CANDIDO, Antonio (2004). "O direito à literatura”. In: Vários escritos. 4.ed. São Paulo/Rio de Janeiro: Duas Cidades/Ouro sobre Azul, p.169-191. (2007). "Pathos e discurso político". In: MACHADO, Ida Lúcia; MENEZES, William; MENDES, Emília (Orgs.). Emoções no discurso, II. Rio de Janeiro: Lucerna, p.240-251.

COLOMER, Teresa (2017). Introdução à literatura infantil e juvenil atual. São Paulo: Global.

ESTEVES, João Pissarra (2016). Sociologia da comunicação. 2.ed. Lisboa: Fundação Calouste Gulbekian.

FERES, Beatriz dos Santos (2011). Leitura, fruição e ensino: com os meninos de Ziraldo. Niterói: EdUFF.

JOUVE, Vincent (2012). A leitura. São Paulo: Editora Unesp..

KOCH, Ingedore; ELIAS, Vanda Maria (2016). Escrever e argumentar. São Paulo: Contexto.

PEIRCE, Charles Sanders (2001). Semiótica. 3.ed. São Paulo: Perspectiva.

RAMOS, Ana Margarida (2011). "A literatura para a infância em Portugal: últimas tendências". In: OLIVEIRA, leda de (Org.). O que é qualidade em literatura infantil e juvenil: com a palavra o educador. São Paulo: DCL, p.201-218.

SATAELLA, Lúcia; NÖTH, Winfried (2005). Imagem: cognição, semiótica, mídia. São Paulo: Iluminuras. 
Beatriz dos Santos Feres é Doutora e Mestra em Estudos da Linguagem pelo Programa de Pós-Graduação em Letras da Universidade Federal Fluminense (2006). Professora Associada de Língua Portuguesa da UFF. Pós-doutoranda na UERJ em Estudos Literários (2020). Atua no Programa de Pós-Graduação em Estudos da Linguagem da UFF, vinculada à disciplina Semiolinguística; nas Especializações em Língua Portuguesa e em Literatura Infantojuvenil e na Graduação em Letras, com orientação de pesquisa em todos os níveis. Autora de Leitura, fruição e ensino: com os meninos de Ziraldo (EdUFF, 2011); organizadora de Leitura e formação do leitor: cinco estudos e um relato de experiência (7Letras, 2016), com Ivo do Rosário e André Dias, e de Análises de um mundo significado: a visão semiolinguística do discurso (EdUFF, 2017), com Rosane Monnerat, entre outros. Autora de vários artigos e capítulos de livro, privilegiando a análise do discurso literário, com ênfase nos contos ilustrados para crianças. É membro do GT da Anpoll Linguística de Texto e Análise da Conversação. Lidera o Grupo de Pesquisa Leitura, fruição e ensino (CNPq/ UFF). É membro do Círculo Interdisciplinar de Análise do Discurso (CiadRio) e do Grupo de Pesquisa A narrativa ficcional para crianças e jovens: teorias e práticas (UERJ).

E-mail: beatrizferes@id.uff.br

ORCID iD: https://orcid.org/0000-0001-5854-2898 